\title{
Algunas reflexiones sobre el método iconológico paranoico de Juan Antonio Ramírez para el estudio de la obra de Dalí
}

\author{
Some thoughts on Juan Antonio Ramírez's \\ iconologic-paranoid method \\ for the study of Dali's works
}

\author{
IvÁn Moure-Pazos \\ Istituto di Studi Superiori (UNIBO) \\ ivan.menes@yahoo.es
}

Recibido: 16 de diciembre de 2014

Aprobado: 8 de junio de 2015

\begin{abstract}
Resumen
En 1990, Juan Antonio Ramírez daba a conocer al mundo académico su método iconológico paranoico. Se trata de un sistema ideado para el estudio de la obra de Dalí, surgido del feliz connubio entre el método paranoico crítico del artista catalán y la primera escuela iconográfica de Warburg y Panofsky. Lo que, en principio, orientaba hacia una metodología extravagante y con poca credibilidad académica, resultó ser, andado el tiempo, un método eficaz para la investigación de las primeras producciones dalinianas. No es de extrañar que, a las puertas del siglo XXI, esta hibridación entre el método de Dalí y el de Panofsky fuera concebida como disparatada y extraña. Sin embargo, veinte años después, sabemos de recientes ejemplos palmarios que avalan las ventajas de este nuevo sistema para el estudio "iconográfico". Como viene siendo común, la nueva aportación de JAR a la metodología de la historia del arte estaría llamada a tener gran pervivencia futura en las generaciones venideras. El presente artículo, trata de analizar este método, indagando en su validez, eficacia y utilidad práctica.

Palabras clave: Juan Antonio Ramírez, método iconológico paranoico, Dalí.
\end{abstract}

Moure-Pazos, I. (2016): Algunas reflexiones sobre el método iconológico paranoico de Juan Antonio Ramírez para el estudio de la obra de Dalí. Arte, Individuo y Sociedad, 28(1) 59-70

\begin{abstract}
In 1990, Juan Antonio Ramírez made known his iconological paranoiac method to the academic world. It is a system devised to study Dalí's work, born of happy matrimony between the catalonian artist's critical paranoiac method and the first iconographic school of Warburg and Panofsky. What, at first sight, seemed to be an extravagant methodology with little academic credibility, turned out to be, by going forward in time, an effective research method when analyzing Dali's initial works. It is no wonder that, at the beginning of XXI century, this hybridization between Dalí's and Panofsky's methods, were regarded as a strange and nonsensical idea. Nevertheless, twenty years after, blatant examples have been noted, which endorse the advantages of this new system for "iconographic" study. As usual, this new contribution by Juan Antonio Ramirez to art history methodology is called upon to have a successful future survival, in forthcoming generations. This article, attempts to analyze this method, inquiring into the validity, effectiveness and practical utility. Keywords: Juan Antonio Ramírez, iconological paranoiac method, Dalí.
\end{abstract}


Sumario: 1. Introducción, 2. ¿Cómo se configura y en qué consiste el método iconológico-paranoico?, 3. ¿Cuál es la utilidad de este método en la obra de Dalí?, 4. Un caso práctico, 5. Conclusiones. Referencias. Notas.

Sus estudios de iconografía y teoría de la arquitectura, de las construcciones imaginarias y fantásticas, de los edificios ideales, de las problemáticas del movimiento moderno, de las metáforas visuales de la cultura de masas, son textos hoy fundamentales que igual atraen la atención de los especialistas como a los lectores cultos que quieren profundizar semánticamente en el arte [...] Ramírez era verdaderamente un hombre universal. Interesado por igual por el mundo del pasado del humanismo que por las actuales vanguardias artísticas, indagaba tanto el legado del renacimiento y del barroco como ahondaba en la significación de las tendencias más radicales de hoy en día. En todos los campos del saber estético profundizaba desvelando siempre nuevas perspectivas. Su capacidad de transmisión oral a través de las lecciones en las aulas era tan grande como la de sus publicaciones. Con su desaparición se pierde un gran maestro.

Antonio Bonet Correa, Juan Antonio Ramírez, historiador y pensador (2009) A mi gran amigo Mauricio Wiesenthal

El presente artículo forma parte del proyecto europeo Performigrations: people are the territory (Dipartimento di Lingue, Letterature e Culture Moderne. Università di Bologna). Analogamente, dicho artículo ha sido posible gracias a la financiación postdoctoral del Plan Galego de Investigación, Innovación e Crecemento 2011-2015 promovido por la Xunta de Galicia.

\section{Introducción}

Sobre el método iconológico se ha escrito mucho, de hecho en esta misma revista fue publicado, no hace mucho, un excelente y didáctico artículo de Alejandra Val Cubero sobre metodología en el análisis de la obra de arte que ilustra y pone de relevancia la utilidad académica de dicho sistema (Val, 2010, pp. 64-66). En líneas generales, y parafraseando a Panofsky, el método iconológico "se ocupa del contenido temático o significado de las obras de arte, en cuanto a algo distinto de su forma" (Panofsky, 1971, p.3), es decir; constituye una fuerte reacción contra el "encorsetamiento" de los estudios formales en el arte figurativo e indaga en el significado oculto de la obra arte.

El sistema gozó de una gran acogida en las universidades de todo el mundo, siendo actualmente uno de los métodos más utilizados por los investigadores para el estudio de las obras de arte.

En 1933, Dalí idea su método paranoico crítico:

Método espontáneo de conocimiento irracional basado en la asociación interpretativacrítica de los fenómenos delirantes [...] La actividad crítica interviene únicamente como líquido revelador de imágenes, asociaciones, coherencias y sutilezas sistemáticas graves y ya existentes en el minuto en que se produce la instantaneidad delirante. (Dalí, 1935, p. 23). 
Dicho método ha sido ampliamente tratado en los estudios de Lourdes Cirlot, (1986, pp. 263-278; 2003, pp. 177-184), Virgili Ibarz y Manuel Villegas (2007, pp. 107-112), Brad Epps (1995, pp.307-320), o Ana Iribas (2004,p. 27) en su artículo para Arte, Individuo y Sociedad bajo la rúbrica de "Salvador Dalí desde el psicoanálisis":

El método paranoico-crítico marcó un nuevo giro en el arte surrealista, alejándolo de la pasividad de los sueños incontrolados y las producciones automáticas. La posición del artista debería ser, en un primer momento, una apertura no controlada a las asociaciones e imágenes inconscientes ("delirios"). En un segundo momento, el artista debería aplicar la inteligencia racional al análisis del material irracional, sistematizándolo y haciéndolo inteligible. Conviene señalar que los delirios poseen en sí mismos un significado sistemático, que sólo se torna claro a la conciencia a través del análisis y la libre asociación. (Iribas, 2004, p. 27).

Todo se complica en 1990 cuando el célebre historiador del arte malagueño, Juan Antonio Ramírez ${ }^{1}$ conjuga, en un ensayo magnífico, sendos métodos. Sobre la hibridación de ambos sistemas, el icónológico y el paranoico-crítico versa el artículo que sigue.

Hace más de dos décadas, JAR sorprendía al mundo académico con la creación de un nuevo método iconográfico: el método iconológico-paranoico; una rehabilitación iconográfica en la que se hermanaba el delirio objetivo de Dalí con la académica ciencia iconológica (Fig. 1) ${ }^{2}$.

Dicho método, desde sus inicios, no estuvo exento de polémica a tenor de las palabras del autor en su último artículo autobiográfico:

La primera vez que formulé esa conexión, en uno de los congresos del CEHA, hubo quien pensó que yo estaba bromeando, pero aunque aprecio mucho el valor intelectual y moral del sentido del humor, hablaba en serio en aquella ocasión. Se trataba de tomar en consideración el motor inconsciente de la creación intelectual, algo que puede ser muy relevante en un seminario como éste en el que intentamos detectar las conexiones entre el trabajo individual y las pulsiones colectivas de la historia. ¿Hasta qué punto es paranoica la intuición que nos lleva a un descubrimiento inesperado? Creo que ofrecí algunas respuestas prácticas, ante casos concretos, en el libro de Dali del que estoy hablando ahora, y también en La metáfora de la colmena. Lo más inquietante es la dificultad de distinguir entre esa paranoia "positiva" que nos permite encontrar directamente una verdad oculta, y la "negativa" que nos conduce al error, o nos impulsa a mantenernos en él con temeraria obcecación. (Ramírez, 2008, p. 522).

Esto, quizás, debido a que:

[...] al método paranoico crítico se le ha concedido un valor meramente poético, en tanto que el iconológico ha alcanzado una inexpugnable posición académica. Mientras el primero sería un desvario humorístico de un artista extravagante, el segundo entraría en el sacrosanto dominio de la ciencia (Ramírez, 2002, p. 135).

Por lo tanto, no es de extrañar que, a las puertas del siglo XXI, esta hibridación entre el método de Dalí y el de Panofsky fuera concebida como disparatada y extravagante. 
Sin embargo, veinte años después, sabemos de las ventajas de este nuevo sistema. Como viene siendo común, la nueva aportación de JAR a la metodología de la historia del arte estaría llamada a tener gran pervivencia futura en las generaciones venideras. Lo que sigue, pretende esclarecer los enigmas de este curioso método, cómo se gesta, en qué se basa, cuál es su utilidad, y cuál su pertinencia en los estudios de Dalí.

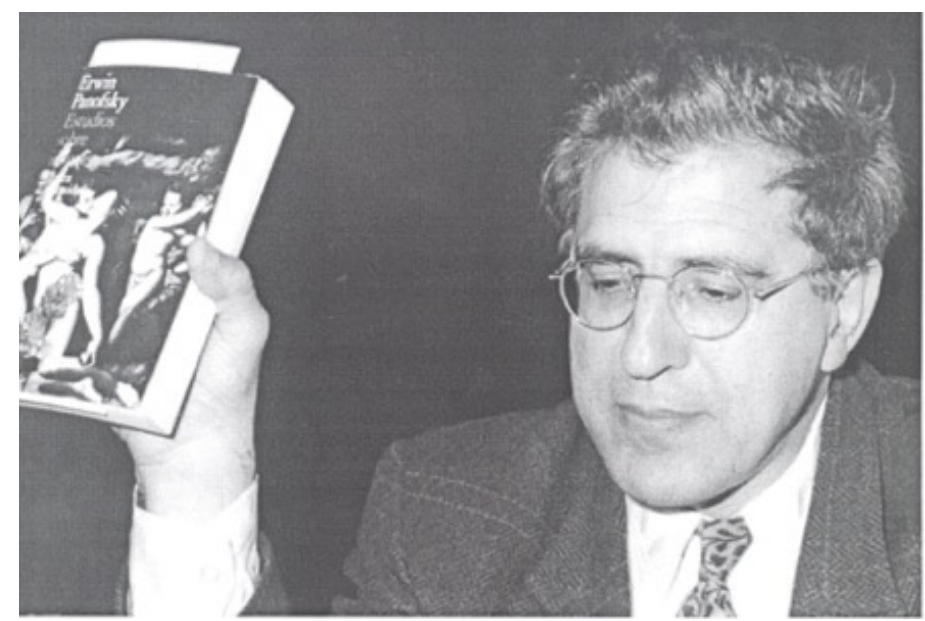

Figura 1. Juan Antonio Ramírez (1948-2009). Foto tomada en la conferencia "Los fallos de la historia del arte" (12-05-1998). El autor sostiene en su mano uno de los libros más influyentes en la historiografía del arte del siglo XX: Estudios sobre iconología de Erwin Panofsky, pieza fundamental de sus reflexiones sobre el método iconológico paranoico. Col. Fundación Juan March.

\section{2. ¿Cómo se configura y en qué consiste el método iconológico-paranoico?}

El método iconológico-paranoico, nace de una serie de puntos en común entre los métodos de Freud ${ }^{3}$, Warburg ${ }^{4}$, Panofsky ${ }^{5}$, y Dalí 6 . Las similitudes en la sistematización de sus respectivos métodos son el punto de partida para llevar a cabo una interrelación de los sistemas:

"Mantengo, pues, la hipótesis de una influencia pendular: en un primer momento Freud influye sobre Warburg; en un segundo estadio, la escuela iconológica (y por supuesto el psicoanálisis) contribuye a que Dali defina mejor su método paranoico crítico". (Ramírez, 1991, p. 19).

Es así como:

La lectura de la obra artística, tanto para el método iconológico como para el paranoico-crítico, se despliega como un tríptico, o como un drama en tres actos. El propósito implícito es demostrarnos, al modo de un buen relato policíaco, que nuestras ingenuas suposiciones estaban equivocadas. (Ramírez, 1991, p. 18).

El método iconológico-paranoico, se nutre, pues, de dos tradiciones metodológicas, hasta el momento, bien diferenciadas: la psicoanalítica y la iconológica ${ }^{7}$. Se trata de una propuesta conciliadora entre sendos métodos que aportan nuevas tablas explicativas sobre Dalí y su obra (Moure, 2011, p. 27). 
Cabe matizar, que el diálogo mantenido entre psicoanálisis e iconología ya había sido tratado por Gombrich en su magnífico libro Freud y la psicología del arte. Estilo, forma y estructura a la luz del psicoanálisis (1971). En él, el autor vienés procede al igual que JAR, rastreando las similitudes entre ambos métodos. Para Gombrich, el símbolo constituiría el principal nexo de unión entre las dos escuelas metodológicas (Gombrich, 1971, pp. 9-47). Así, pues, nos aclara: "Un motivo de un cuadro del Bosco puede representar un navío destrozado, simbolizar el pecado de la gula y expresar una fantasía sexual inconsciente por parte del artista" (1983, p. 214). Lo que pretende Gombrich es romper los límites de la primera iconología o iconología pura, a fin de introducir una nueva fuente de información en la obra de arte: la del propio artista y su simbolismo personal (Ocampo; Perán, 2002, p. 147).

Estamos, por consiguiente, ante una continuación de los planteamientos metodológicos llevados a cabo por Gombrich. Lo novedoso de JAR, es que actualiza la relación entre psicoanálisis e iconología, al conjugar estas teorías con el método paranoico crítico de Dalí. Por lo tanto, JAR parte de este fecundo diálogo y lo hace extensible al delirio voluntario del propio Dalí, a fin de crear nuevos vínculos metodológicos. El producto de este trasvase, fructificará en el llamado método iconológico-paranoico, donde la relación entre iconología y psicoanálisis, y viceversa resulta incuestionable (Moure, 2011, p. 28):

Llamaremos a este método, que se reclama conscientemente heredero de Panofsky mientras paga un tributo inconsciente al genial artista catalán, iconológico-paranoico. Su importancia es excepcional: extendido hoy por las universidades de todo el mundo, parece haber alcanzado una posición dominante respecto a las otras opciones metodológicas. No creo que nuestro artista catalán haya soñado en vida con semejante triunfo intelectual. (Ramírez, 2002, p. 136).

\section{3. ¿Cuál es la utilidad de este método en la obra de Dalí?}

Una vez configurado el sistema iconológico-paranoico, cabe preguntarse por su aplicación empírica, por su utilidad a la hora de extraer información de una obra de Dalí. Es aquí donde debemos valorar si el método de JAR funciona, o por contra, ha de considerarse un ejercicio intelectual circunscrito únicamente al campo teórico.

Una de las mayores ventajas o aciertos del método iconológico-paranoico, es que, ya en su planteamiento inicial, nos permite conjugar el simbolismo personal del propio artista con su obra, en contraposición a una iconografía más tradicional, basada en documentos hipercodificados y ampliamente socializados como única explicación al motivo figurativo. Algo que, practicamente viene impuesto por las propias fuentes surrealistas, influenciadas, en gran medida, por los diferentes escritos psicoanalíticos. Difícilmente pudiéramos abordar el método paranoico crítico de Dalí -fuertemente deudor de los postulados freudianos- sin tener en consideración su patrimonio afectivo. Igualmente frustrante hubiese sido tratar con producciones automatistas desde un enfoque genuinamente iconográfico, pongamos por caso un Cadavre exquis. Y es que un sistema tan rígido, al tratar con el surrealismo y Dalí, traería consigo el riesgo de la sobreinterpretación, ese gran descrédito de la disciplina iconológica (Moure, 2011, p. 28). En pleno S. XXI, sabemos de los peligros del 
método iconográfico. Es Gombrich, quien nos advierte por primera vez sobre el vicio de la sobreinterpretación ${ }^{8}$. El modo de evitarla, es según el autor, localizar el "programa" o "libreto"; es decir, dar con un sistema bien documentado que verifique nuestra hipótesis. Sólo así: "se puede hacer corresponder una ilustración compleja con un texto que dé cuenta de sus principales rasgos", prueba irrefutable de "que el iconógrafo ha demostrado lo que pretendía" (Gombrich, 1983, pp. 5-7).). Al tratar con Dalí, ésto obliga a considerar su patrimonio afectivo -sueños, traumas, complejos y demás- como parte de su producción simbólica.

Pasándonos al extremo contrario, tratar de explicar la obra daliniana desde un ángulo psicoanalítico devendría forzosamente en escepticismo, pues, el símbolo se tornará indefinido y críptico, solamente revelado tras el largo análisis de los contenidos inconscientes del autor. También aquí será común la sobreinterpretación, ahora sobre la vivencia del artista, acotándose el campo de la emblemática a las diferentes neurosis individuales; es decir, el arte como síntoma de una patología (Moure, 2011, p. 28).

Conscientes de estos peligros, JAR - siguiendo a Gombrich- opta por un sistema iconográfico permeable al símbolo en su acepción más amplia, a fin de comprender la obra del artista catalán de la manera más objetiva posible. Es aquí donde reside la verdadera fuerza del método iconológico paranoico, en su perfecta adecuación al análisis de la obra de Dalí. Por lo tanto, tal sistema busca neutralizar los excesos y defectos de ambos métodos, ofreciéndonos una alternativa muy bien medida entre iconología y psicoanálisis. Al tratar con un artista tan excelso como Dalí, donde el manierismo de sus repertorios iconográficos se entrevera constantemente con su simbología personal, el método de JAR emulsiona como eficaz viático para el estudio de su emblemática.

\section{Un caso práctico}

Pongamos un ejemplo. Tomemos como caso práctico un análisis de la La miel es más dulce que la sangre (1927) de Dalí (Fig. 2) -actualmente desaparecido-; consumación de un estudio previo del mismo nombre (Fig. 3) ${ }^{9}$. En el reciente artículo titulado "Nuevas hipótesis sobre La miel es más dulce que la sangre de Dalí" bajo rúbrica de Iván Moure, podemos apreciar uno de los más esclarecedores abordajes de la obra de Dalí en base a esta metodología, desvelándose sorprendentes hallazgos "iconográficos" (Moure, 2012, pp. 181-192): 


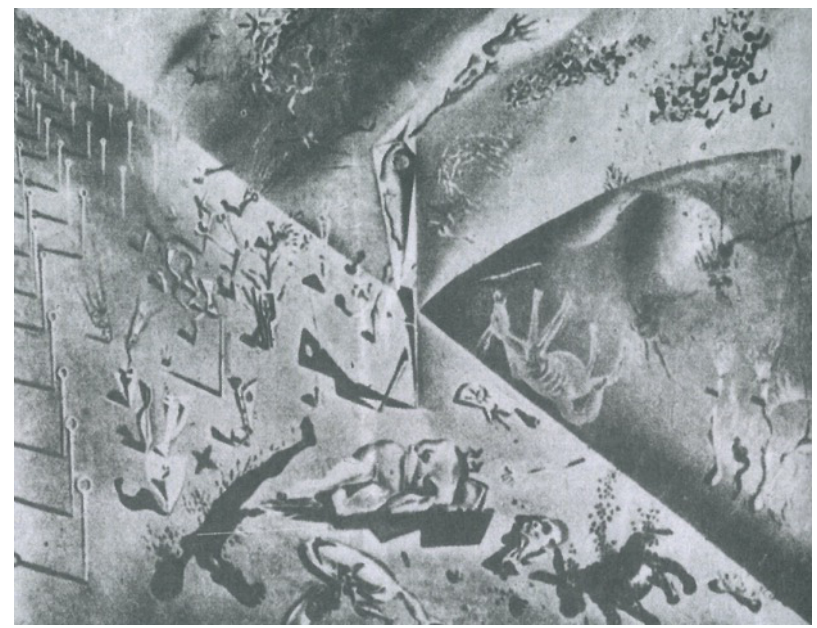

Figura 2. Dalí. La miel es más dulce que la sangre. 1927. Paradero desconocido.

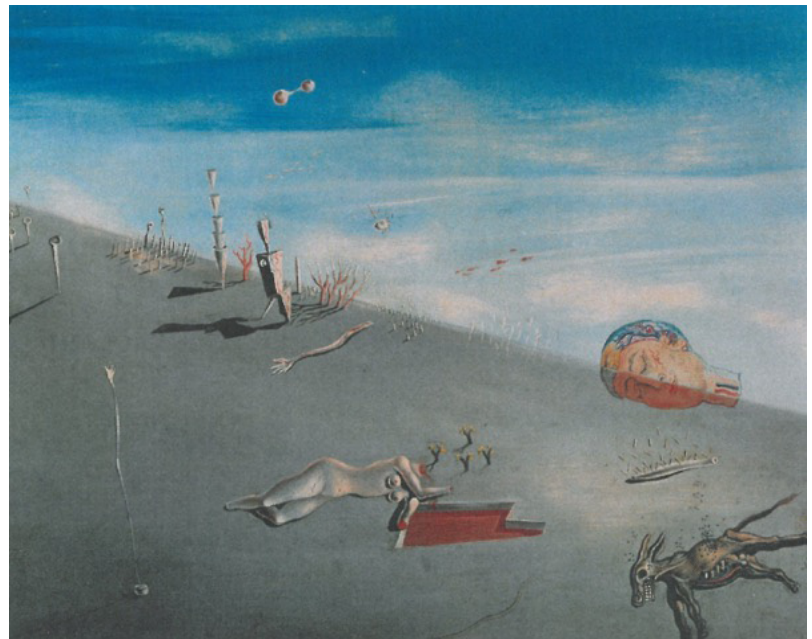

Figura 3. Dalí. Estudio para La miel es más dulce que la sangre. 1926. Col. Fundación Gala-Salvador Dalí.

Comencemos por el título del cuadro. Sabemos por Ian Gibson que Dali leyó al Conde de Lautréamont -pseudónimo de Isidore Ducasse- en la residencia de estudiantes de Madrid, probablemente por influjo directo de Lorca, o indirecto de Rubén Dario. Por consiguiente, hemos de iniciar este análisis, considerando que Dali ya conocía la obra de Lautréamont con anterioridad a la ejecución de La miel es más dulce que la sangre. Por ello, no ha de sorprendernos, que el título del cuadro haya sido puesto por Agustín Sánchez Vidal, Fèlix Fanés y Pilar Parcerisas, en relación con el canto segundo del poeta uruguayo-francés: "O mathématiques sévères, je ne vous ai pas oubliées, depuis que vos savantes leçons, plus douces que le miel, filtrèrent dans mon coeur, comme une onde refraîchisante”, que nos muestra, de manera clarividente, la toma daliniana de Les Chants de Maldoror (1868). Ya tenemos, por lo tanto, la primera información del cuadro: el título hace referencia a un pasaje del 
Conde de Lautréamont. Sigamos profundizando en nuestro análisis. En el lateral izquierdo, vemos una sucesión de agujas de coser alusivas al célebre pasaje surrealista extraído del Canto VI de Les Chants de Maldoror: "Il est beau comme comme la recontre fortuite sur une table de dissection d'une machine à coudre et d'un parapluie”. Por consiguiente, un segundo elemento pone en relación el cuadro con el Conde de Lautréamont. Giramos la cabeza, y tendidos sobre el terreno, observamos los cráneos decapitados de Lorca y Dalí, que constituyen una de las bases fundamentales de la teoría lorquiana de La miel es más dulce que la sangre, esgrimida por Rafael Santos Torroella en su estupenda tesis La miel es más dulce que la sangre: las épocas lorquiana y freudiana de Salvador Dalí (1984, pp. 326-331). Cerca de sendos cráneos, observamos dos "carnuzos" o burros putrefactos devorados por un bastión de insectos. Se trata de una crítica furibunda hacia lo caduco y lo burgués, y por ende, al propio padre de Dali, reconvertido, andando el tiempo, en la figura del "burócrata". Lo mismo pudiera decirse del tiburón situado a los pies del cuadro, aunque éste, también podría admitir una lectura lautreamontiana, relacionada con el Canto II de Les Chants, en el cual, tiene lugar el apareamiento de Maldoror con el escualo. Salpicando el cuadro en todas direcciones, emulsionan un montón de manos y brazos sectorializados, vinculados con la impotencia sexual del pintor y sus traumas sicalípticos. De igual manera, nos encontramos con esos peligros fecundadores que son los pólemicos espermatozoides alados, sobrevolando una tierra destronada de belleza y putrefacción (Moure, 2012, pp. 186-187).

Podríamos proseguir con el análisis del cuadro, pero considero que para nuestro cometido, ya tenemos suficientes elementos simbólicos que constatan la pertinencia del método iconológico paranoico en la tela de Dalí.

En la obra, se entremezclan, en clave lautreamontiana, la cultura iconográfica de Dalí (el título del cuadro, las agujas de coser, y el tiburón) con el propio patrimonio afectivo del pintor (Lorca, los "carnuzos", los brazos sectorializados y los espermatozoides alados). Estamos, por lo tanto, ante un cuadro donde convergen -a través de pócimas paranoico críticas- la cultura emblemática del autor con su exorcismo vital. El resultado, es una caterva de símbolos -de procedencias disparesque totalizan en el método iconológico paranoico.

Con todo, cabe reseñar que este sistema -al igual que los anteriormente mencionados- también tiene sus peligros, por lo que cabe proceder con cautela:

Se trataba de tomar en consideración el motor inconsciente de la creación intelectual, algo que puede ser muy relevante en un seminario como éste en el que intentamos detectar las conexiones entre trabajo individual y las pulsiones colectivas de la historia. ¿Hasta qué punto es paranoica la intuición que nos lleva a un descubrimiento inesperado? [...] Lo más inquietante es la dificultad de distinguir entre esa paranoia positiva que nos permite encontrar directamente una verdad oculta, y la negativa que nos conduce al error, o nos impulsa a mantenernos en él con temeraria obcecación. (Ramírez, 2008, p. 522).

\section{Conclusiones}

Después de todas estas páginas, parece ineludible constatar esa influencia psiconalítica iconológica en el método paranoico crítico de Dalí, germen, como sabemos, del sistema iconológico paranoico diseñado por JAR. Éste -siguiendo a Gombrichdesarrolla una métodología de gran eficacia y utilidad para el historiador del arte. $\mathrm{Su}$ gran acierto, estriba en el logro de una mayor objetividad en el estudio de las 
obras de Dalí. Su operatividad, abarca la totalidad de las producciones dalinianas, ya sean tempranas, meridianas o finales, proporcionándonos un amplio muestrario de aquellas imágenes simbólicas que comportan el universo daliniano ${ }^{10}$. Hecho a valorar, en un artista que gusta de la reutilización de elementos, llegando a crear auténticos alfabetos iconográficos a través de su simbología; algo tomado por Breton y los surrealistas para desacreditar su obra, sobre todo, aquella posterior a los años treinta, acusándola de poco original (Sánchez, 2007, pp. 12-15) ${ }^{11}$.

Por lo tanto, quisiera apostillar que el repertorio daliniano, se mueve siempre entre dos aguas, o dos tradiciones metodológicas: de un lado el psicoanálisis criptofreudiano, del otro, los postulados panofskyanos, ambos, contenidos en el método paranoico crítico de Dalí, y por extensión, en el sistema iconológico-paranoico rehabilitado por JAR para el estudio específico de las imágenes dalinianas.

Quisiera, como coda final, concluir este artículo con unas palabras del recientemente fallecido historiador malagueño extraídas de su iluminador escrutinio sobre Dalí:

Esta síntesis singular entre la escuela de Warburg y la herencia daliniana puede ser vista con el ceño fruncido por la sospecha o bien, como yo prefiero, con un guiño de complicidad. En cualquier caso, es bueno reconocer que la iconología (y todo el conjunto de la ciencia) no se aleja tanto como parece del delirio objetivo de la tradición surrealista. Los métodos, en sí mismos, tienen una validez relativa. Para el historiador del arte, como para el artista mismo, lo importante es la calidad de los resultados, y eso es algo que se incrementará siempre que seamos capaces de sazonar nuestro trabajo con elevadas dosis de lucidez sin olvidar del todo el sentido del humor. (Ramírez, 2002, p.136).

\section{Referencias}

Ades, D. (2004): "Estudio para La miel es más dulce que la sangre", en Dawn Ades (Ed.), Catálogo de la exposición Dalí, celebrada con motivo de su centenario en el Palazzo Grasi de Venecia (90-93). Madrid: La esfera de los libros. (Del 12 de septiembre de 2004- 16 de enero de 2005).

Bonet, A. (2009, 15 de septiembre). Juan Antonio Ramírez, historiador y pensador. El País. Recuperado de http://elpais.com/diario/2009/09/15/ necrologicas/1252965602_850215.html.

Bou, E. (2004). Daliccionario. Objetos, mitos y símbolos de Salvador Dalí. Barcelona: Tusquets.

Cirlot, L. (1986). El método paranoico-crítico de Dalí y su aplicación a la lectura del “Ángelus" de Millet. D'Art. Revista del departament d'Historia de l'Arte, (12), 263-278.

- (2003). Dalí y el “Ángelus” de Millet. Pandora, revue d'etudes hispaniques, (3), $177-184$.

Dalí, S. (1935). La conquista de lo irracional. París: Éditions Surréalistes.

Dalí, S. (2003). El mito trágico de El Ángelus de Millet, en Joan Vinyoli (trad.), Obra Completa de Salvador Dalí, (403-549), Vol. V. Barcelona: Destino, Fundación Gala-Salvador Dalí, Sociedad Estatal de Conmemoraciones Culturales. 
- (2003). Visión paranoica, en Eduard Castano (trad.), Obra Completa de Salvador Dalí, (466-472), Vol. IV. Barcelona: Destino, Fundación Gala-Salvador Dalí, Sociedad Estatal de Conmemoraciones Culturales.

Descharnes, R. (1984). Dalí: la obra y el hombre. Barcelona: Tusquets.

Epps, B. Figuración, narración, liberación. El método paranoico-crítico de Salvador Dalí. Revista de lenguas y literaturas catalana, gallega y vasca, (4), 307-320.

Fanés, F. (2003). Prólogo, en Salvador Dalí, Obra Completa de Salvador Dalí, (7-47), Vol. I. Barcelona: Destino, Fundación Gala-Salvador Dalí, Sociedad Estatal de Conmemoraciones Culturales.

- (1999). Salvador Dalí. La construcción de la imagen. 1925-1930. Madrid: Electa.

Fernández, B. (2004). De Rabelais a Dalí: la imagen grotesca del cuerpo. Valencia: Universitat de València.

Freud, S. (2001). Dostojewski y el parricidio, en Sigmund Freud, Obras Completas, T. II, Madrid: Biblioteca nueva.

- (2001). El Moisés de Miguel Ángel, en Sigmund Feud, Obras Completas, T. II. Madrid: Biblioteca nueva.

- (2001). Un recuerdo infantil de Leonardo da Vinci, en Sigmund Freud, Obras Completas, T. II. Madrid: Biblioteca nueva.

- (2001). Un recuerdo infantil de Goethe, en Poesía y verdad en Sigmund Freud, Obras Completas, T. II. Madrid: Biblioteca nueva.

Gibson, I. (2004). Dalí joven, Dalí genial. Madrid: Santillana.

Gombrich, E. (1983) Imágenes simbólicas. Estudios sobre el arte del renacimiento II. Madrid: Alianza.

- (1971). Freud y la psicología del arte. Estilo, forma y estructura a la luz del psicoanálisis. Barcelona: Barral.

Ibarz, V; Villegas, M. El método paranoico-crítico de Salvador Dalí. Revista de historia de la psicología, vol. 28 (2), 107-112.

Iribas, A. Salvador Dalí desde el psicoanálisis. Arte, Individuo y Sociedad, (Vol. 16), 19-47.

Lautréamont, C. (1988). Los cantos de Maldoror, en Manuel Álvarez Ortega (trad.) y Maurice Saillet (prologuista)., Obra completa bilingüe (42-527). Madrid: Akal.

Moure, I. (2012). Nuevas hipótesis sobre La miel es más dulce que la sangre de Dalí. Archivo español de arte, (22), 181-192.

- (2011). El bestiario del Conde de Lautréamont: la invocación daliniana. (Tesis doctoral inédita). Universidad de Santiago de Compostela, Santiago de Compostela.

- (2010). Víctimas y verdugos en las ilustraciones de Les Chants de Maldodor de Dalí. Anuario del departamento de historia y teoría del arte de la universidad autónoma de Madrid, (22), 225-239.

Ocampo, E., Peran, M. (2002). Teorías del arte. Barcelona: Icaria.

Panofsky, E. (1984). El significado de las artes visuales. Madrid: Alianza.

- (1983). La perspectiva como forma simbólica. Barcelona: Tusquets.

- (1971). Estudios sobre iconología. Madrid: Alianza. 
Parcerisas, P. (2010). Dalí y Ducasse. La sombra de Maldodor, en Juliette Murphy (Comisaria)., Catálogo de la exposición Salvador Dalí. Les Chants de Maldoror. 1934, (133-139). Figueres: Distribucións d'Art Surrealista. (Del 13 de marzo de 2010 al 31 de diciembre de 2010).

Pérez, J. (2003). Salvador Dalí: a la conquista de lo irracional. Madrid: Algaba.

Ramírez, J. A. (2008). Los poderes de la imagen: para una iconología social (esbozo de una autobiografía intelectual). Boletín de Arte, (29), 509-537.

- (2002). Dalí: lo crudo y lo podrido. Madrid: Antonio Machado Libros.

- (1996). Iconografía e iconología, en Valeriano Bozal (Coord.), Historia de las ideas estéticas y de las teorías artísticas contemporáneas (227-244). Madrid: Visor.

- (1991). El método iconológico y el paranoico crítico. Ars Longa, (2), 15-20.

Sánchez, A. (2007). Salvador Dalí. Madrid: Fundación MAPFRE.

- (1988). Buñuel, Lorca, Dalí: el enigma sin fin. Barcelona: Planeta.

Santos, R. (2005). El primer Dalí. 1918-1929. Valencia: IVAM y Generalitat Valenciana.

- (1984). La miel es más dulce que la sangre: las épocas lorquiana y freudiana de Salvador Dalí. Barcelona: Seix Barral.

Val Cubero, A. (2010). Una aproximación metodológica en el análisis de las obras de arte. Arte, Individuo y Sociedad, (22) 2, 63-72.

Warburg, A. (1999). Aby Warburg, The renewal of pagam antiquity. Los Ángeles: Getty Research Institute.

\section{Notas}

1. En lo sucesivo JAR.

2. Dicho método fue presentado primero como comunicación en el VIII Congreso del Comité Español de Historia del Arte (Cáceres, 3-6 de octubre de 1990). Un año después, se publicaría en con el título de "El método iconológico y el paranoico crítico", en Ars Longa, $\mathrm{n}^{\circ} .2$, 1991, pp. 15-20. A partir de entonces, el artículo, integrado en un contexto más extenso, verá la luz en dos nuevas publicaciones bajo las rúbricas: "Iconografía e iconología", en Historia de las ideas estéticas y de las teorías artísticas contemporáneas, Madrid, Visor, 1996, pp. 227-244 (Coord. Valeriano Bozal); y Dali: lo crudo y lo podrido, Madrid, Antonio Machado Libros, 2002, pp. 121-136. Fue, sin duda, el éxito de este último libro el que más contribuyó a la difusión de su método. Mese antes de fallecer, Juan Antonio Ramírez publica en su artículo autobiográfico "Los poderes de la imagen: para una iconología social (esbozo de una autobiografía intelectual)", Boletín de Arte, (29), p. 533: "Se recogen en este libro tres ensayos dedicados a Salvador Dalí: en el primero de ellos se abordan cuestiones como las visiones del cuerpo y del amor que mantuvo el artista ampurdanés; el segundo está dedicado a su concepción de la arquitectura (se analizan sus distintos "clasicismos"); el tercero se ocupa de mostrar las relaciones entre el método iconológico, de gran abolengo en la historia del arte, y el paranoico-crítico elaborado por Dalí".

3. Vid. Sigmund FREUD, en especial: "Un recuerdo infantil de Leonardo da Vinci" en Freud, Sigmund, Obras Completas, T. II, Madrid, Biblioteca nueva, 2001, p. 971; "El Moisés de 
Miguel Ángel” en Freud, Sigmund, Obras Completas, T. II, Madrid, Biblioteca nueva, 2001, p. 977; "Un recuerdo infantil de Goethe en Poesía y verdad" en Freud, Sigmund, Obras Completas, T. II, Madrid, Biblioteca nueva, 2001, p. 1036; "Dostojewski y el parricidio" en Freud, Sigmund, Obras Completas, T. II, Madrid, Biblioteca nueva, 2001, p. 1044.

4. Vid. Aby WARBURG, Aby Warburg, The renewal of pagam antiquity, Los Ángeles, Getty Research Institute, 1999.

5. Se recomiendan especialmente los siguientes libros del autor, en los cuales expone sus planteamientos iconológicos: Erwin PANOFSKY, Estudios sobre iconología, Madrid, Alianza, 1971; La perspectiva como forma simbólica, Barcelona, Tusquets, 1978; El significado de las artes visuales, Madrid, Alianza, 1983.

6. Vid. Salvador DALÍ, "El mito trágico de «El Ángelus» de Millet” en Obra Completa de Salvador Dalí, Vol. V, Barcelona, Destino, Fundación Gala-Salvador Dalí, Sociedad Estatal de Conmemoraciones Culturales, 2003, pp. 403-549. (Trad, Vinyoli, Joan); "Visión paranoica" en Obra Completa de Salvador Dalí, Vol. IV, Barcelona, Destino, Fundación Gala-Salvador Dalí, Sociedad Estatal de Conmemoraciones Culturales, 2003, pp. 466-472. (Trad. Castaño, Eduard).

7. Juan Antonio RAMÍREZ, "El método iconológico y el paranoico crítico", en Ars Longa, $\mathrm{n}^{\circ} .2,1991$, pp. 15-16.

8. Ernst GOMBRICH, Imágenes simbólicas. Estudios sobre el arte del renacimiento II, Madrid, Alianza, 1983, pp. 5-7. Tema también abordado por Erwin PANOFSKY, El significado...op. cit., p. 51. "Hay que reconocer que existe un cierto peligro de que la iconología se comporte no como la etnología en relación con la etnografía, sino como la astrología en relación con la astrografía".

9. La obra escogida no es baladí, ya que, hoy -lunes 11 de abril de 2011 - la Fundación GalaSalvador Dalí exhibe en el Teatro-Museo Dalí el estudio del mismo nombre realizado por el pintor catalán, después de haber sido adquirida por dicha Fundación el 10 de febrero del mismo año, en una subasta abierta por Christie's por la nada desdeñable cifra de 4.794.215 euros.

10. Por producciones tempranas, nos referimos a las surgidas entre los años 20 y 40, por meridianas a las realizadas en los años 50 , y por finales o de madurez a las tres últimas décadas.

11. Agustín SÁNCHEZ VIDAL, Salvador Dali, Madrid, Fundación MAPFRE, 2007, pp. 12-15. 